\title{
Micropyrotechnics, a new technology for making energetic microsystems: review and prospective.
}

\author{
C. Rossi ${ }^{*}, \mathrm{D}$. Estève \\ LAAS-CNRS, 7 avenue du colonel Roche
}

31077 Toulouse cedex 4

\begin{abstract}
$\underline{\text { Abstract }}$
A review of the micropyrotechnics related works is done. Micropyrotechnics is the integration of an energetic material into microsystem, for which the thermal, mechanical and chemical energy released by decomposition can be exploited. After a state-of-the art of micropyrotechnics and its application to microsystems, authors try to identify obvious difficulties and insufficiencies that may require future work, particularly in terms of the development of new materials, new modelling tools and new processes for integration into microsystems. A section is dedicated to the current micropyrotechnic applications including emerging ones. In conclusion, the perspectives of this discipline are discussed and the authors try to give some guidelines for future investigations.
\end{abstract}

\section{Nomenclature}

$\begin{array}{ll}T_{s} & \text { Surface temperature } \\ T_{i} & \text { Temperature of initiation } \\ T_{o} & \text { Initial temperature } \\ T_{\text {ambient }} & \text { Ambient temperature } \\ C_{p} & \text { Heat capacity of the energetic material }\end{array}$

\footnotetext{
${ }^{*}$ Tel : 335613363 01; FAX: 33561336208

e.mail : $\underline{\text { rossi } a \text { laas.fr }}$
} 


\begin{tabular}{|c|c|}
\hline$C_{p, g}$ & Heat capacity of the combustion gas \\
\hline$\rho_{p}$ & Density of the energetic material \\
\hline$k_{p}$ & Thermal conductivity of the energetic material \\
\hline$t$ & Time \\
\hline$\tau$ & Time step \\
\hline Pelect & Input electrical power over the time \\
\hline$S$ & Surface area over which the electrical flux is applied \\
\hline$\phi$ & Input electrical flux \\
\hline$\phi_{c}$ & Critical ignition flux \\
\hline$t_{i c}$ & Critical ignition time \\
\hline$V_{r}$ & Rate of combustion of the energetic material \\
\hline$V_{M A X}$ & Maximal combustion rate \\
\hline$a^{2}$ & Section of energetic material in combustion \\
\hline$a_{\text {critical }}$ & Quenching diameter \\
\hline$L$ & Thermal loss in the environment \\
\hline$k_{s}$ & Thermal conductivity of the surrounding material \\
\hline$T_{f}$ & Flame temperature \\
\hline$Q$ & Heat release \\
\hline$D P$ & Over pressure \\
\hline$V p$ & Energetic material volume \\
\hline Vo & Initial volume \\
\hline$h$ & Convection coefficient \\
\hline$h_{s}$ & Convection coefficient between combustion gas and the surrounding material \\
\hline
\end{tabular}

\section{INTRODUCTION}

Obtaining an integratable, compatible, low cost energy source providing a sufficient quantity of easily accessible energy within a miniaturized system has been an ongoing challenge for decades. The urgency and interests of such systems will continue to increase with the development of portable microsystems [1] [2][ 3], distributed microsystems $[4][5][6][7]$ as the smartdust type [8] and monitoring systems. The most reasonable option in the next few years is to distribute energy needs between multiple onboard sources adapted to specific needs. Naturally, a large amount of scientific work is being done on miniature electrical sources [9][10][11][12]. A 
similar effort is being done to find solutions to mechanical and/or thermal actuation problems [13][14]. This is the context of our analysis.

The conventional approach to mechanical actuation is based on electromagnetic machines. This option is very efficient but difficult to integrate at microscopic scales [15]. Actuation making use of electrostatic forces $[16][17][18]$ became widespread starting from the 1990s, and this is an important step forward for microsystems since it is very easy to integrate, it is relatively powerful and easy to use. However, its use is limited to small displacements. Obviously it does not satisfy all needs, and there is still a real one to be satisfied for integrated and high power actuation.

About 1995, the use of energetic materials began to attract interest in the scientific community since they are a very attractive source of onboard energy. For example, combustion of these materials is an attractive means of obtaining a large quantity of energy from a small volume. Typically, the combustion of hydrocarbon materials produces $50 \mathrm{MJ} / \mathrm{kg}$, combustion of propellant produces $5 \mathrm{MJ} / \mathrm{kg}$, while a modern chemical lithium battery used in new laptops only stores $0.4 \mathrm{MJ} / \mathrm{kg}$. Thus, even with a conversion efficiency of $10 \%$, propellants are still attractive in terms of available energy density. To return to mechanical actuation applications, it would be better to use the actuation pressure parameter, that is defined as the ratio between the energy and the volume of the system. Table 1 compares actuation pressures for different actuation methods developed in microsystem technology. It shows that propellants are capable of accessing to the most attractive actuation pressures.

If these materials could be integrated into functional microsystems in a manner compatible with microsystem technologies, then micropyrotechnics could help to make considerable progress in the field of power microactuation and energy micro storage.

Table 1. Comparison of different actuation available in terms of actuation pressure

\begin{tabular}{|l|l|}
\hline Type of actuation & $\begin{array}{l}\text { Actuation pressure } \\
\left(\mathrm{J} / \mathrm{m}^{3}\right)\end{array}$ \\
\hline Piezoelectric (PZT) & $10^{5}$ \\
\hline Electrostatic & $10^{3}$ \\
\hline Electromagnetic & $10^{5}$ \\
\hline Thermomechanic & $\sim 10^{5}$ \\
\hline Thermopneumatic & $10^{6}$ \\
\hline Shape memory alloy & $10^{7}$ \\
\hline SMA) & \\
\hline
\end{tabular}




\begin{tabular}{|l|l|}
\hline Solid-liquid phase change & $10^{6}$ (acetimine) - \\
& $10^{7}$ (paraffin) \\
\hline $\begin{array}{l}\text { Energetic material } \\
\text { combustion }\end{array}$ & $10^{7}-10^{8}$ \\
\hline
\end{tabular}

In this context in which LAAS-CNRS initiated micropyrotechnics in 1997 for medical applications by proposing and making micropyrotechnics actuators [19][20]. It then applied the concept to micropropulsion for space [21]. Since then, other teams have initiated large amounts of work in micropyrotechnics by integrating energetic materials (propellants or explosives) into microsystems to generate micro-thrusts $[22][33][34][35][36][37][38][39][40]$, gases for actuation [42], for micro-initiation [24][43] or simply to act as energy sources to modify surfaces, and for heating and welding [44]. This large number of applications suggests that approaches should be coded. We can talk about a new discipline called « micropyrotechnics ». This term includes various orientations presented in the specialised literature as « explosives technology » [46] or « micro detonic » [44] by other teams. Some of these teams, and especially American teams, have emphasized this prospect and participate in exploration of this discipline. For example, Stewart et al have published work on integration and operation of explosives (initiation and detonation) with small dimensions (of the order of a millimetre) [44][46][47]. In Europe, Rossi et al have published work on propellant integration technologies in millimetric structures and on microinitiation and combustion aspects at this scale [52][53]. Menon et al have developed processes based on micro and nano technologies to generate high energy compounds in very thin layers, and to characterize their initiation capacity [45]. The Menon's scale is a few atomic layers. These works are very recent and some is only being published now.

Note that although micropyrotechnics was initiated in 95-97 to solve a fluid actuation (empty a tank) and micropropulsion problem for space applications, it has become diversified and enriched:

1. in its applications: nowadays, micropyrosystems are used in applications for intelligent micro initiation for weapons, shells, surface micromachining, microwelding, controlled gas generation $\ldots[42][37][44][45]$.

2. in technology and integrated materials: the earliest propulsion units integrated " off the shelf » propellant materials, but the current trend is to develop energetic materials with controlled performance and that are compatible with microsystem technologies [24][25][27][30]. 
3. in dimensions: the volume of the earliest pyrotechnic actuators was $6 \mathrm{~mm}^{2}$ [20], but now the dimensions of similar applications have been reduced to the order of $1 \mathrm{~mm}^{2}$ and the trend for miniaturisation in initiation is continuing by developing energy materials with high efficiency in thin layers [45][26].

Faced with this wide range of applications, we considered that it would be useful to draw up the current status of this discipline in terms of: (i) the technological development, (ii) the modelling, and, (iii) the applications that we will describe briefly. The overall aim is to identify obvious remaining insufficiencies requiring fast and more detailed investigation, particularly in terms of the development of new materials and new processes for integration into microsystems. But we will firstly define « micropyrotechnics ».

\section{WHAT IS MICROPYROTECHNICS?}

Micropyrotechnics can be defined as the integration of an energetic material into a multi-functional microsystem, for which the thermal, mechanical and chemical energy released by decomposition can be exploited. The chemical energy can be released by sublimation, or combustion, or detonation conditions. This approach is promising because:

1. The concept is very simple: all that is necessary is to know how to deposit a mass of energetic material and integrate a heating platform at the same location.

2. The system is flexible: the stored energy and the pressure generated depend on the volume of energetic material, such that it can be adapted to various applications.

3. The release of energy or generation of pressure is triggered by electrical signal and is therefore fully controllable by electronics.

4. A wide variety of usages may be made depending on the application: for example, decomposition gases can be used to generate a thrust. The combustion heat can be used directly for local heating and to satisfy very high energy needs (for example welding, stripping). Combustion heat can also be transformed into electrical or mechanical energy, or specific gases can be generated [29][41].

\section{SCIENTIFIC AND TECHNOLOGICAL CHALLENGES}

Apart from the energetic material that is inherently the heart of the system, the other central element of micropyrotechnics is the heating platform that initiates and maintains decomposition of the energetic material. The emergence of micropyrotechnics and the production of reliable and high performance micropyrosystems are closely related to the capacity to find and develop good heaters. They must be able to initiate energetic material with powers compatible with microsystems, and able to assure a complete decomposition of them despite their 
small dimensions. The last but not least point is to be able to insert the energetic materials into the global microsystem depending on the application. These lead to the following challenges:

1. Optimisation of initiation is a crucial point for the progress of this technology. The objective is to minimise the energy to be supplied to trigger the initiation such that these systems are compatible with microsystem constraints. This point will be discussed in the section MODELLING OF THE MICRO INITIATION.

2. The reduction of the dimensions towards the limits of micropyrotechnics, to make further progress in the integration level, mass and cost reduction. This point will be discussed further in the TOWARDS OPTIMUM INTEGRATION section.

3. The choice of energetic materials to be integrated. The energetic material is at the heart of the technology. It must be selected and formulated precisely as a function of the application and as a function of the expected performances in terms of initiation and actuation. This point will be discussed in the CHOICE OF THE ENERGETIC MATERIALS section.

4. The choice of architecture and the development of a simple, integratable, robust and reliable manufacturing and assembly technology. These points will be discussed in the CHOICE OF THE TECHNOLOGIES AND STRUCTURAL MATERIALS section.

\section{MODELLING OF THE MICRO-INITIATION}

It is essential to have a good understanding of the phenomena involved, to fully control a technology. This understanding also helps to develop design tools for new, reliable and optimised systems. Two main aspects need to be understood and modelled in order to control micropyrotechnics at very small dimensions: (1) the initiation with the search of the optimum power and the critical surface area, and (2) the combustion to know the critical operating conditions (flame extinction). We will discuss the first aspect in this section, and the second one in the next section.

Initiation obviously depends on the nature of the initiator support and the quality of the thermal contact between the material and the heating platform. To present this modelling work, we will assume the case of heating by a resistance on a thin dielectric membrane made from silicon substrate. Others options are possible $[43][22][35][24][42]$ but will not be considered in this study.

\subsection{Case of intimate thermal contact}

We assume that deposition of the energetic material is fully managed, thus providing a perfect intimate thermal contact between the initiator and the material. Initiation is a thermal phenomenon (eq 1): the electrical energy 
input to the propellant initially at $22^{\circ} \mathrm{C}$ increases its temperature at the surface and around (see Figure 1). When the surface temperature $\left(T_{s}\right)$ exceeds the ignition temperature $\left(T_{i}\right)$, an exothermal reaction takes place. Ignition is successful if the energy released is sufficient, despite losses, to maintain the heating temperature up to $T_{i}$. When thermal losses into the environment occur, there is a critical size of the hot point below which initiation will not occur. The question that arises is : considering losses, is the electrical power sufficient to heat the surface of the propellant up to its ignition temperature? And if so, for how long do we need to apply the power? This is the purpose of the following models to avoid long, difficult and expensive experimentations.

$C_{p} \rho_{p} \frac{\partial T}{\partial t}=\lambda\left(\frac{\partial^{2} T}{\partial x^{2}}+\frac{\partial^{2} T}{\partial y^{2}}+\frac{\partial^{2} T}{\partial z^{2}}\right)+L$

$L$ includes losses by convection $h\left(T_{s}-T_{\text {ambient }}\right)$; radiation losses are negligible for temperatures below $300^{\circ} \mathrm{C}$.

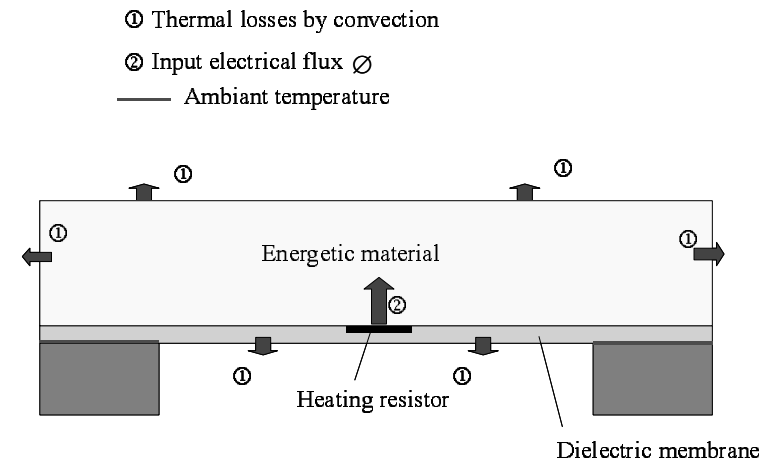

(a)

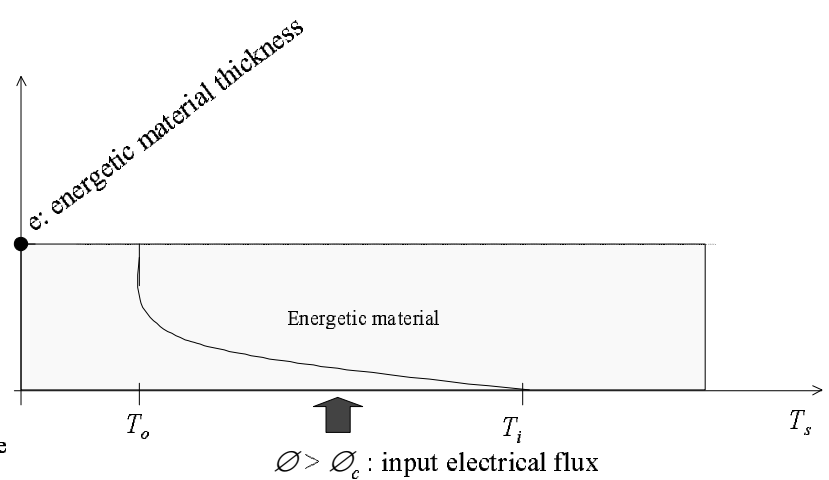

(b)

Figure 1. (a) Thermal flux during initiation and (b)thermal profile in the material thickness during a successful initiation

To illustrate this work, we will consider energetic material based on $\mathrm{GAP}^{1}$ and $\mathrm{PA}^{2}$ for which the depth of the thermal profile $\left(\sqrt{k_{p} / \rho_{p} C_{p} \times t}\right)$ is about $600 \mu \mathrm{m}$ after $250 \mathrm{~ms}$. This means that a semi-infinite wall can be assumed for thicknesses of more than $1 \mathrm{~mm}$. Thus, the heating of the propellant per unit area can be written simply:

\footnotetext{
${ }^{1}$ Glycidyl Azide Polymer

${ }^{2}$ Ammonium Perchlorate
} 
$T_{s}(t)=T_{o}+\frac{1}{\sqrt{\pi k_{p} \rho_{p} C_{p}}} \int_{o}^{t} \phi(t) \frac{d \tau}{\sqrt{t-\tau}}$

where $\phi(t)=\operatorname{Pelect}(t) / S$

This assumption does not take account of lateral losses but it provides an easy way of making a first estimation of the initiation time as a function of electrical powers, as shown in Figure 2. If the thickness of the deposited material is less than $1 \mathrm{~mm}$, we cannot assume that the wall is semi-infinite and the ignition problem becomes a classical thermal problem to be solved numerically with finite element software. The same curves could be plotted but requiring longer calculation times.

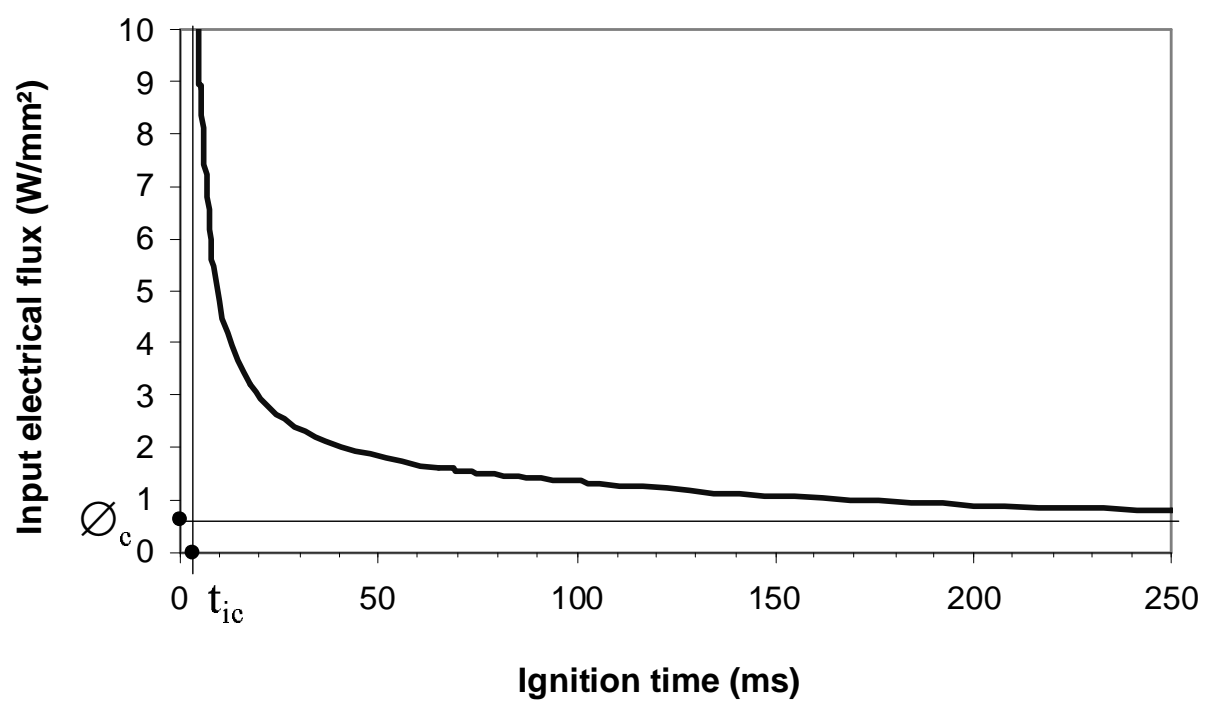

Figure 2. Initiation time as a function of the density of incident electrical power $(\varnothing)\left(T_{i}=300^{\circ} \mathrm{C}\right)$

Note that there are very intense energy fluxes ( $\phi$ for time less than $t_{i c}$ ) which do not enable initiation of the combustion. Regarding these fluxes, the propellant is degraded while the flux is applied, and then all reactions stop. The propellant degrades too quickly and the pre-heated area close to the wall is too thin to maintain the combustion. In microsystems, in which the problem is to minimise electrical energy, this problem does not arise. There is a critical flux $\left(\phi_{c}\right)$ under which initiation is not possible even if the flux is applied hours.

If we consider an ignition temperature $T_{i}$ equal to $300^{\circ} \mathrm{C}$, the graph in Figure 3 shows that times between $16 \mathrm{~ms}$ and $88 \mathrm{~ms}$ are necessary to initiate the propellant combustion, depending on the incident electrical powers between 100 and $200 \mathrm{~mW}$. For lower powers (for example $100 \mathrm{~mW}$ ), no initiation is possible. 


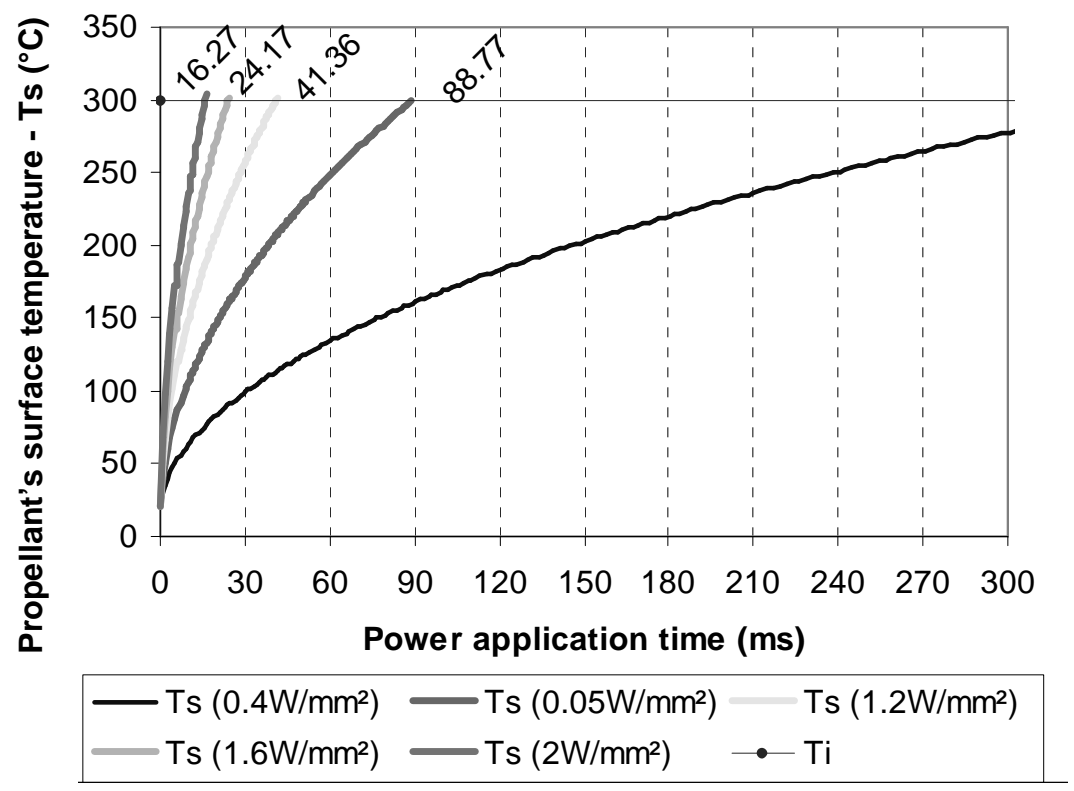

Figure 3. Initiation duration as a function of electrical ignition powers assuming that the ignition point is on the surface

These calculations need to be carried out for each material in each heating platform as a function of the application, to determine the optimum point for initiation.

\subsection{Case of non-intimate thermal contact - failure of initiation}

The above results assume that contact is intimate between the heating platform and the material. If it is not, the required power and energy are much greater than the values predicted by calculations. This situation is not exceptional for two reasons:

1. firstly, the technology used for the deposition of the energetic material onto its heating platform can be defective: air bubbles can be created between the energetic material and the heating platform during the deposition.

2. secondly, the energetic material and the membrane supporting the hot point separate while heating to the initiation temperature, due to the difference in expansion coefficients between the two parts.

This was demonstrated by experiments using the initiation resistance as a thermal sensor during the initiation process. Figure 4 shows an example. It can be seen that the temperature of the resistance after $1 \mathrm{~ms}$ is much 
higher than $T_{i}$, although initiation did not take place. This demonstrates that there is a micro air bubble between the resistance and the energetic material. This is an essential technological problem in micropyrotechnics that must be solved to assure optimum initiation and reproducibility. One solution is to deposit a thermal layer between the two parts.

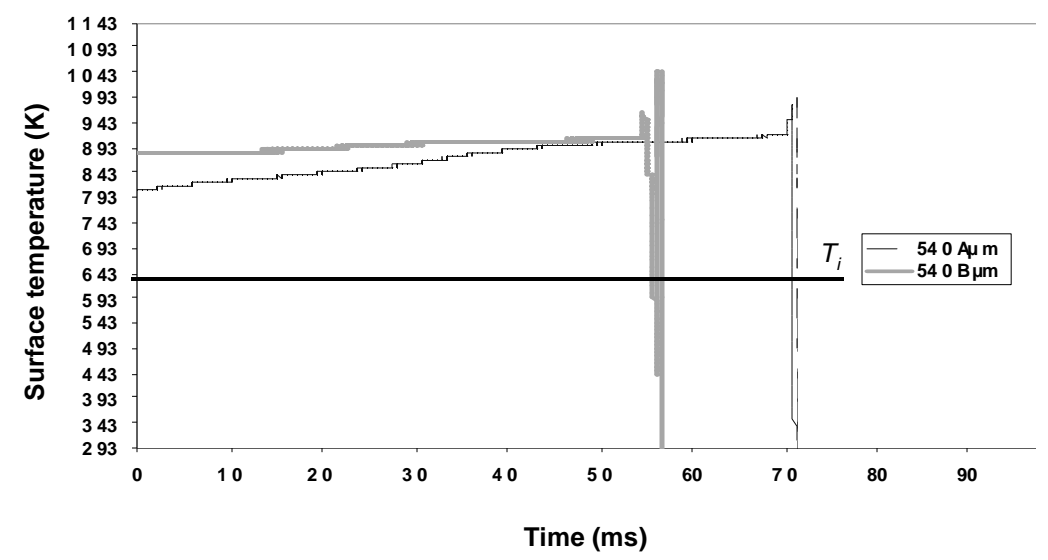

Figure 4. Initiation curves for a non-intimate energetic material/platform contact (540 A $\mu \mathrm{m}$ and $540 \mathrm{~B} \mu \mathrm{m}$ are the names of the samples)

\section{TOWARDS OPTIMUM INTEGRATION - SEARCH FOR THE CRITICAL SECTION OF COMBUSTION}

Micropyrosystem dimensions depend on the target application and expected performances in terms of required gas volume or required force... The objective for all teams is to achieve optimum integration, for obvious mass saving reasons. For example, one targets a maximum available energy to structure weight ratio. However, this miniaturisation approach cannot be dissociated from the search for a sufficient operating reliability: when the dimensions are reduced below the critical combustion area, the material combustion energy-to-heat loss ratio is such that it becomes more difficult to sustain the propagation of the combustion. Therefore it is essential to be able to predict these critical operation dimensions to develop reliable structures. Rossi et al have proposed a simple model for predicting the combustion rate $\left(V_{r}\right)$ as a function of the section in combustion $\left(a^{2}\right)$ and as a function of losses in the environment $(L)$. The modelled system is shown in Figure 5. The flame front that corresponds to the section in combustion moves at a rate $V_{r}$ Combustion is self-maintained by heating of the propellant in contact with the flame front at its ignition temperature $\left(T_{i}\right)$. 


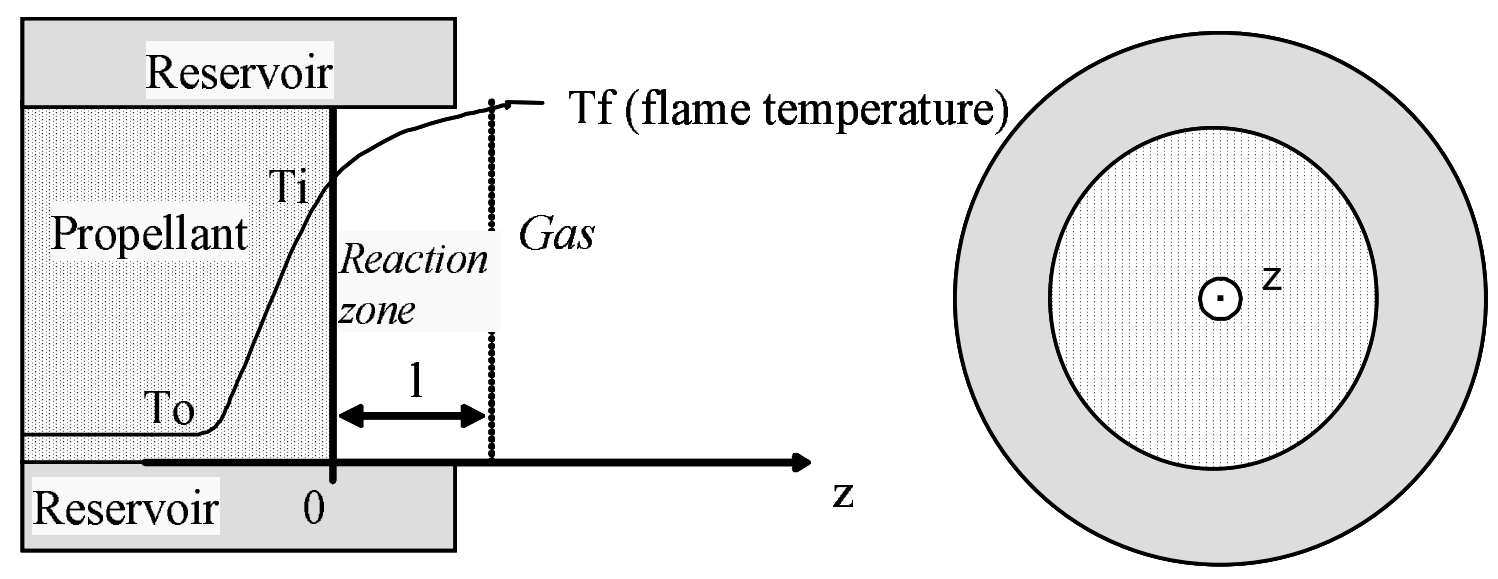

Figure 5. Schematic view of the modelled system and thermal profile of a tube of propellant in combustion

$k_{p} \frac{\partial^{2} T}{\partial z^{2}}-\rho_{p} C_{p} \frac{\partial T}{\partial t}=L$

where $L$ is the heat loss into the environment.

Equation 3 is written as a function of the combustion rate $V_{r}$ :

$k_{p} \frac{d^{2} T}{d z^{2}}+\rho_{p} V_{r} C_{p} \frac{d T}{d z}=L^{\prime}$

Solution of equation 4 gives expressions for the combustion rate $V_{r}$ and the critical combustion diameter $a_{\text {critical }}$ as a function of losses. The parameter $V_{M A X}$ is obtained empirically by measuring the combustion rate of a propellant tube with a diameter greater than $1 \mathrm{~cm}$ surrounded by a highly insulating material $(\mathrm{k}<0.1 \mathrm{~W} / \mathrm{mK})$. The flame temperature $\left(T_{f}\right)$ is estimated assuming that the entire combustion energy of the material $(Q)$ is transmitted to the flame: $T_{f}=T_{i}+\frac{Q}{C_{p, g}}$

Table 2. Expression of the combustion rate and the critical diameter for different thermal environment

\begin{tabular}{|l|l|l|}
\hline Thermal environment & Combustion rate expression & Quenching diameter \\
\hline No thermal loss $L=0$ & $V_{r}=V_{M A X}$ & $/ / / / / / /$ \\
$\bullet L=S_{s} h_{s}\left(T-T_{0}\right)$ & $V_{r}=V_{M A X}\left[1-\frac{4 k_{p} h_{s}}{a h_{p}^{2}} \frac{\left(T_{i}-T_{0}\right)^{2}}{\left(T_{f}-T_{i}\right)^{2}}\right] ;$ & $a_{c r i t i c a l}=\frac{4 k_{p} h_{s}}{V_{M A X} \rho_{p}^{2} C_{P}^{2}}$ \\
$\bullet L^{\prime}=\frac{4 h_{s}}{a}\left(T-T_{0}\right)$ & with $h_{p}=V_{M A X} \rho_{p} C_{p} \frac{\left(T_{i}-T_{0}\right)}{\left(T_{f}-T_{i}\right)}$ & \\
\hline
\end{tabular}




\begin{tabular}{|l|l|l|}
\hline \begin{tabular}{l|l|} 
Conductive thermal losses \\
$\qquad=S_{s} k_{s} \frac{\partial T}{\partial x}$
\end{tabular} & $V_{r}=V_{M A X}\left[1-\frac{4 k_{s}}{a h_{p}} \frac{\left(T_{i}-T_{0}\right)}{\left(T_{f}-T_{i}\right)}\right] ;$ & $a_{c r i t i c a l}=\frac{4 k_{p}}{V_{M A X} \rho_{p} C_{P}}$ \\
$\bullet L^{\prime}=\frac{4 k_{s}}{a} \frac{\partial T}{\partial x}$ & with $h_{p}=V_{M A X} \rho_{p} C_{p} \frac{\left(T_{i}-T_{0}\right)}{\left(T_{f}-T_{i}\right)}$ & \\
\hline
\end{tabular}

In table 2 are reported the expressions of the combustion rate and the quenching diameter for different thermal environment. The graph in Figure 6 illustrates the model. It shows the variation of the combustion rate of a GAPbased composite propellant contained in a Foturan reservoir assuming that lateral losses are conduction losses in the Foturan. In this configuration, the combustion rate decreases very quickly with the combustion section and the critical combustion size is equal to $940 \times 940 \mu \mathrm{m}^{2}$.

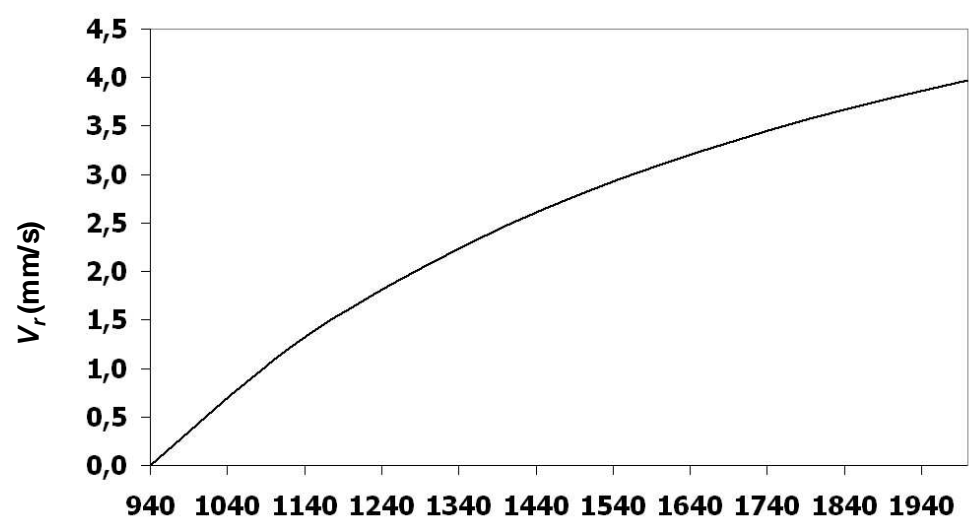

a $(\mu \mathrm{m})$

Figure 6. Combustion rate $\left(V_{r}\right)$ as a function of the diameter of the GAP-based propellant tube (a) surrounded with Foturan (conduction losses)

It can be seen that the order of magnitude of the dimensions of pyrotechnic propellant based systems is about a millimetre. 


\section{THE CHOICE OF THE ENERGETIC MATERIALS}

We have just seen that the energetic material controls design options, and particularly dimensions. Until very recently, teams working on micropyrotechnics explored two options: (i) available « safe » fairly insensitive materials such as homogenous or composite propellant, and (ii) class 1 materials that are highly sensitive and energetic. The recent trend is to develop new materials with « tailored» performances: not very sensitive to shocks and friction, but containing sufficient energy to support combustion despite very small dimensions. No doubt this is the path that will be followed for applications in the future. We will take a look at these different material options:

1. Safe propellant «off the shelf» type materials can sustain combustion originating from an oxidation-reduction reaction when a surface has reached its ignition temperature $\left(T_{i}\right)$. Rates of selfsustained combustion in these materials are relatively low, of the order of a few millimetres to a few centimetres per second as a linear phenomenon. They are used for three main reasons:

- These materials are stable in combustion. Deflagration is only possible under very particular environmental conditions (very strong confinement and high energy input), that are impossible in microsystems.

- The objective of the propellant combustion reaction is to release a very large quantity of gas at high temperature that makes them particularly attractive for propulsion and actuation, the main applications of micropyrotechnics.

- The variety of « of the shelf » propellants is very large (homogenous, simple base, double base, composite), and materials more or less adapted to the constraints of target applications can be formulated. Composite propellants (with energetic binder (for example GAP) or non-energetic onr (for example HTPB)) have a viscous physical appearance before reticulation and a solid appearance after, so that a silk screen printing method can be used to deposit and fill a small cavity [28]. American and European teams [19][21][24][30][35][36][38][40] have preferred the use of these materials. The limiting operating sizes of these systems are about $\varnothing 800 \mu \mathrm{m}$.

2. Class 1:1 materials as explosives such as Lead Styphnate are used [22] for systems smaller than $1 \mathrm{~mm}^{3}$. Under favourable conditions, they are capable of releasing their potential energy within a very short time in a very fast chemical reaction called an detonation. Decomposition releases a large volume of gas, high temperature and a sudden pressure rise. This phenomenon is no longer a reaction propagating by heat transfer like combustion that we modelled above. A pressure wave develops. 
Risks of explosion with low volumes are low, so that it is quite feasible to use these materials to make extremely powerful and compact microactuators.

3. The third approach is to formulate new energetic materials derived from composite propellants, for example by adding very small metallic particles $(<\mu \mathrm{m})$ to them or by modifying the proportion of fuel/oxidizing [27][30] in order to better adapt them to the constraints of the target application. Ali et al propose new materials (based on $\mathrm{C}_{4} \mathrm{H}_{4} \mathrm{~N}_{12} \mathrm{O}_{3}$ and $\mathrm{C}_{4} \mathrm{H}_{4} \mathrm{~N}_{12} \mathrm{O}_{4}$ ) which have better propulsion performances (Isp and combustion rate) than conventional propellants while remaining in the propellants class. Heather et al [24] and Diaz et al [25] add metals ( $\mathrm{Al}$ or $\mathrm{Zr}$ ) to composite propellants in order to increase their combustion rate, so as to increase their propulsion performances and their sensitivity to initiation without increasing their vulnerability to impact and friction. This approach is entirely new (2003 and 2004 publications) but is very promising for future applications.

\section{THE CHOICE OF THE TECHNOLOGIES AND STRUCTURAL MATERIALS}

All teams have chosen microsystem manufacturing technologies for well-known reasons : high capacity for miniaturisation, low costs and machining precision. Silicon is the base material in microsystems. However, there are limits to its use. Its high thermal conductivity $(140 \mathrm{~W} / \mathrm{mK})$ is an advantage in microelectronics to dissipate heat, but it is a serious disadvantage when making high performance micropyrosystems requiring heat confinement. Other materials then have to be envisaged to make pyrotechnic material reservoirs and combustion chambers. The following options are possible to remain compatible with silicon:

- Pyrex: Pyrex has the advantage of having very low thermal conductivity $(1.4 \mathrm{~W} / \mathrm{mK})$. It can also be used to make initiators [35].

- Photosensitive glass is attractive since it has the same thermal characteristics as Pyrex and is chemically machined by processes compatible with microsystem technologies [22][40][52] .

- MACOR $^{3}$ type ceramic that has the advantage compared with glass of having an expansion coefficient very similar to silicon therefore reducing the risks of mechanical failure of the assembly when high temperature gradients and pressure are applied to it. MACOR is machined by conventional method [21].

- An Alumina type ceramic has been used by an American team despite its relatively high thermal conductivity $(30 \mathrm{~W} / \mathrm{mK})[38]$.

${ }^{3}$ made by Sceram : http://www.sceram.com 
- Very recently, polymer (SU8) and plastic substrates have been envisaged for gas generators in microfluidic applications. They have very attractive thermal conductivities, and their cost is very low so that they are attractive particularly for throwaway products [37][41][42].

The main steps in the process for manufacturing micropyrosystem structures (micro thermal initiators and micro reservoirs) use conventional microsystem processes that are now well controlled. We have standardised the following processes:

- deposition of thin films by LPCVD (Low Pressure Chemical Vapor Deposition),

- thermal oxidation and PECVD (Plasma Enhanced Chemical Vapor Deposition),

- photolithography,

- deposition and photolithography of Solgel and BCB type polymer films,

- RIE (Reactive Ion Etching) and DRIE (Deep Reactive Ion Etching) to etch films or the silicon substrate,

- metallisation by evaporation of chromium and gold,

- $\mathrm{KOH}$ wet etching for silicon or dilute HF for Foturan.

On the other hand, integration of the energetic material on the initiator and in the reservoir is a difficult problem. One needs to be able to make a precise deposit on areas of a few $\mathrm{mm}^{2}$ or less, with thicknesses of $10 \mu \mathrm{m}$ to $500 \mu \mathrm{m}$. For some applications, these same materials have to be injected into small blind reservoirs. These deposition techniques must be controlled and have good quality (no air bubbles) to achieve intimate contact between the initiator and the energetic material (see $\S 4.2$ ). Several teams [21][28][42] have proposed filling techniques derived from the silk screen printing, since it is a collective method.

\section{MICROPYROTECHNICS APPLICATIONS}

The airbag is the most well known application of micropyrotechnics [48][49][50][51], followed by the generation of forces which is the most researched use of micropyrotechnics: more than half of the research papers addressing the applications of micropyrotechnics focus on micropropulsion. This concerns the development of microthruster arrays for the space industry and to a lesser degree for the military. Drug injection is also an application that has generated important research in Europe. Other applications are emerging and present very interesting and innovative perspectives in this field, such as fluid microactuating or the production of electrical microgenerators. We will briefly present each of these applications in order to highlight the impact of micropyrotechnics. 


\subsection{Solid micropropulsion}

Thrusters are used in the propulsion and guidance of missiles and shells, and for the orientation and propulsion of satellites and launch rockets. The space and military sectors are clearly interested in the new perspectives in miniaturization.

Concerning the space industry, bigger satellites are likely to be complemented by clusters of nanosatellites $(<20 \mathrm{~kg})$ or picosatellites $(<1 \mathrm{~kg})$. These small spacecrafts will need very small and very precise forces to ensure their relative positioning, orbital manoeuvring, position maintenance, attitude control and deorbiting. Concerning the military, mini- and micro-drones will need small thrusters to ensure their stability in pitch, roll and yaw. For each of these applications, the selection of one propulsion option over another is dictated by the thrust specifications, but also on the basis of weight, volume and cost. In this context, several teams are pursuing the development of solid propellant micropropulsion on silicon. Depending on the uses intended and thus the required levels of forces $(\mu \mathrm{N}$ or $10 \mathrm{mN})$, three approaches were proposed between 1997 and 2000 and have been developed since then by several teams in Europe, the USA and Asia:

- $\quad$ solid propellant propulsion being an assembly of several substrates and aiming for impulsions around $10 \mathrm{mN}$.s, has been initiated by the LAAS-CNRS for space applications [21] and recently extended to military applications,

- « digital» propulsion, aiming for impulsions below $1 \mathrm{mN}$.s has been initiated by an American team made of TRW, Aerospace and Caltech for space applications [22],

- « planar » propellant propulsion, aiming for impulsions above $10 \mathrm{mN}$.s, has been initiated by Berkeley University, for civil or military applications [39].

Table 3 summarizes the different approaches in terms of dimensional characteristics and performances. It also shows the research initiated since 2000 by new teams and categorizes them according to the approaches defined above. 
Table 3. Current status of the various options in micropropulsion on silicon and associated projects

\begin{tabular}{|c|c|c|c|}
\hline & \multicolumn{2}{|c|}{ Several wafers stacked Architecture } & Planar architecture \\
\hline Options & Solid propellant micropropulsion [21] & « Digital » micropropulsion [22] & « Planar » micropropulsion [38] \\
\hline Schematic view & $\begin{array}{l}\text { Nozzle wafer } \\
\text { Igniter } \\
\text { wafer } \\
\begin{array}{l}\text { Propellant } \\
\text { reservoir }\end{array}\end{array}$ & From David H. Lewis et al [22] & $\underbrace{\text { Propellant }}$ Chamber, throat, \\
\hline $\begin{array}{l}\text { Energetic } \\
\text { material }\end{array}$ & $\begin{array}{l}\text { Propellant : ZPP for the igniter and GAP/Zr for } \\
\text { the chamber }\end{array}$ & $\begin{array}{l}\text { High sensitive material : } \\
\text { Lead Styphnate }\end{array}$ & Propellant : HTBP/AP \\
\hline $\begin{array}{l}\text { Chamber } \\
\text { diameter }\end{array}$ & $500 \mu \mathrm{m}-1 \mathrm{~mm}$ & $300 \mu \mathrm{m}-700 \mu \mathrm{m}$ & $3 \mathrm{~mm}$ \\
\hline Throat diameter & $100-500 \mu \mathrm{m}$ & $190-300 \mu \mathrm{m}$ & $500 \mu \mathrm{m}-1 \mathrm{~mm}$ \\
\hline Thrusters & 16 thrusters on $144 \mathrm{~mm}^{2}$ & 15 thrusters on $36 \mathrm{~mm}^{2}$ & $/ /$ \\
\hline
\end{tabular}




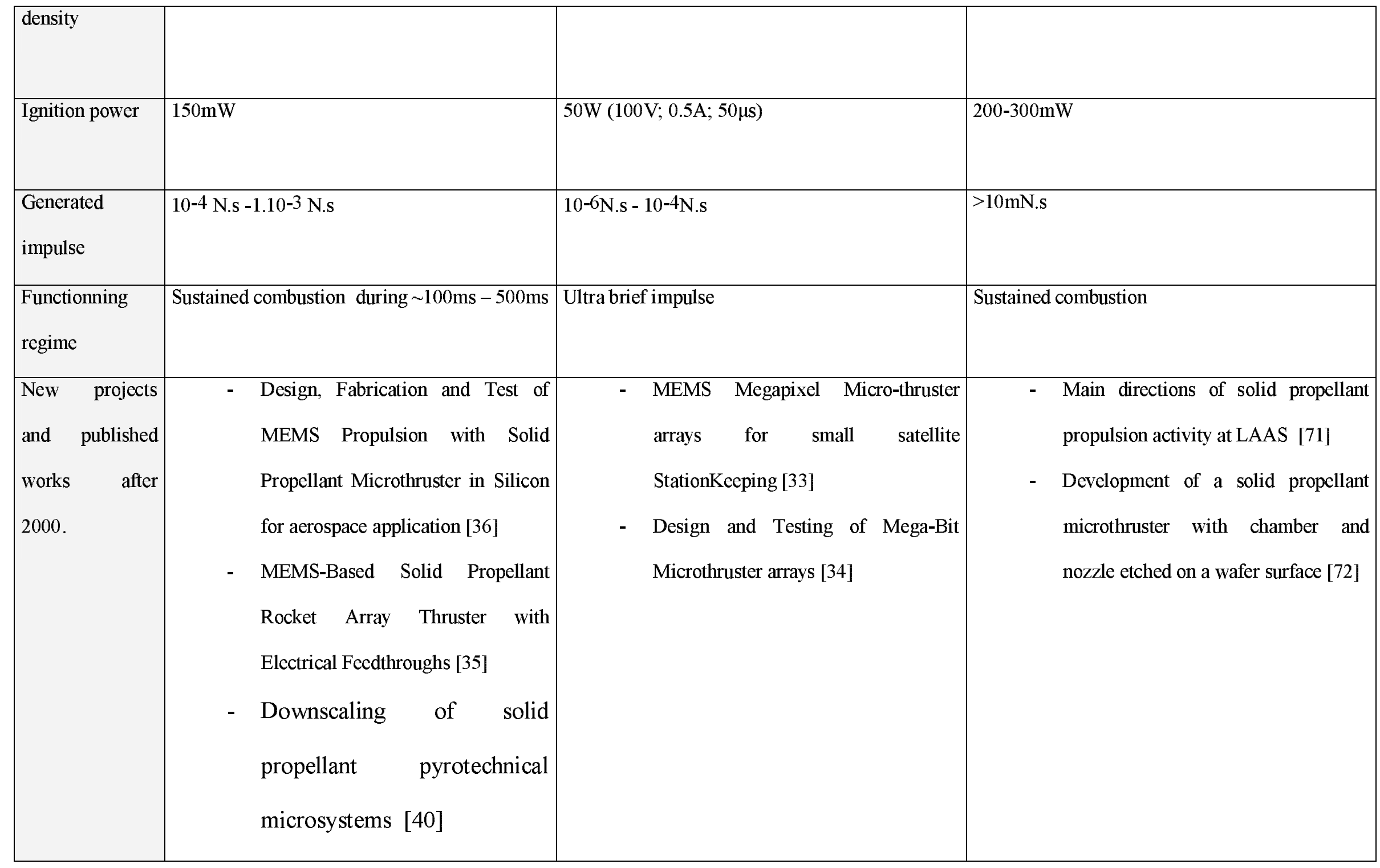




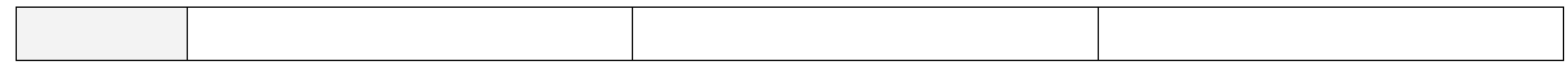


These propositions all use the same principle: a heating resistor integrated on silicon or another substrate initiates the decomposition of an energetic material (propellant or explosive); however, they can be differentiated on four points:

1. The type of energetic material. The use of explosive ensures a chemical reaction even at very tiny sizes (reservoir diameter $<600 \mu \mathrm{m}$ ). But their reaction is unstable and difficult to control, which is why some teams prefer propellants.

2. The architecture of thrusters. A «vertical» architecture consists of stacking up independently fabricated substrates that each defines a part of the structure: initiator, chamber, nozzle. Another « planar » architecture aims to fabricate the whole thruster on the silicon substrate via a single microfabrication.

3. Ignition location (back side or front side). The front side ignition (gas release side) requires the availability of a technology that allows the production of heating resistors on dielectric membranes, sufficiently robust to withstand the filling up and ignition, but also sufficiently thin to be able to break when pressure increases [54].

4. The size of each thruster and the density. The size of each thruster depends on the targeted performance and application: for example, in attitude control we will use impulses around $10^{-6}$ N.s, whereas position maintenance and orbital operations will require more powerful impulses, on the order of $10^{-4}-10^{-3}$ N.s.

Solid propellant micropropulsion on silicon is thus an extremely interesting option because it implements a simple technology and delivers medium specific impulses ( 100s). It consumes low energy for its functioning $(<250 \mathrm{~mW})$ which gives it one of the most interesting yields or specific powers $(\mathrm{mN} / \mathrm{W})$ among all of the options currently developed. Its current technological maturity allows us to anticipate validating this concept in real systems.

\subsection{Drug injection}

Since the 1990s, therapeutic research has used microtechnologies to find and implement new solutions in order to increase the efficiency of treatments while improving the comfort and security of patients. Beyond the miniaturization of systems, the interest lies in the «smart» and automatic administration of the injection. Many teams are working on implantable drug delivery systems [67][68][69]. In the case of non-implantable, simple, 
low cost devices that require a single or limited number of injection doses, micropyrotechnics is an interesting solution. It offers pneumatic microactuators or very inexpensive pyrotechnic gas generators, allowing the administration of programmed injections. The over pressure $(D P)$ that they are able to generate is a function of the ratio $V p / V o$, where $V o$ represents the initial volume of the system in which the energetic material is integrated, and $V p$ is the volume of the energetic material. Figure 7 shows that it is possible to regulate the pressure, from a few to dozens of bars, by adjusting the proportions of the volumes of energetic material and initial one.

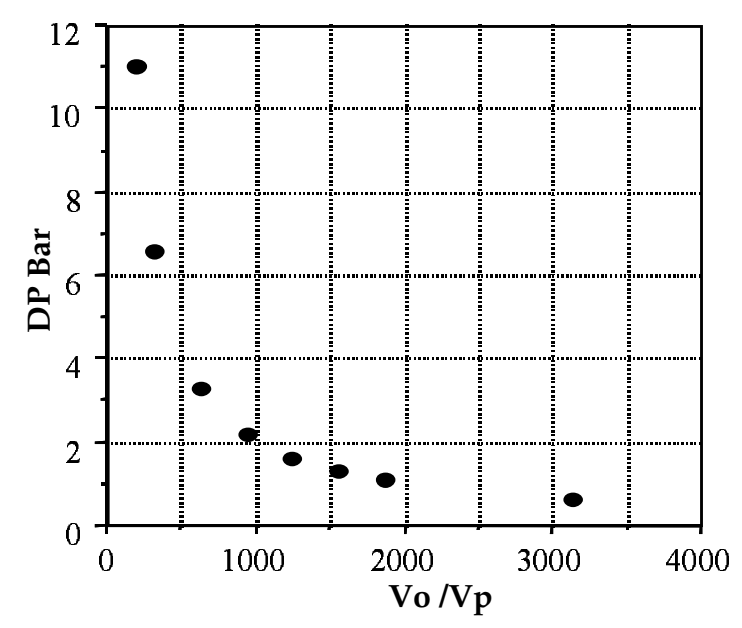

Figure 7. Generated pressure $(D P)$ as a function of the ratio energetic material volume / initial volume

It also allows the fabrication of one-shot microvalves [55][56] by breaking a fine membrane with the combustion gases as shown in Figure 8.

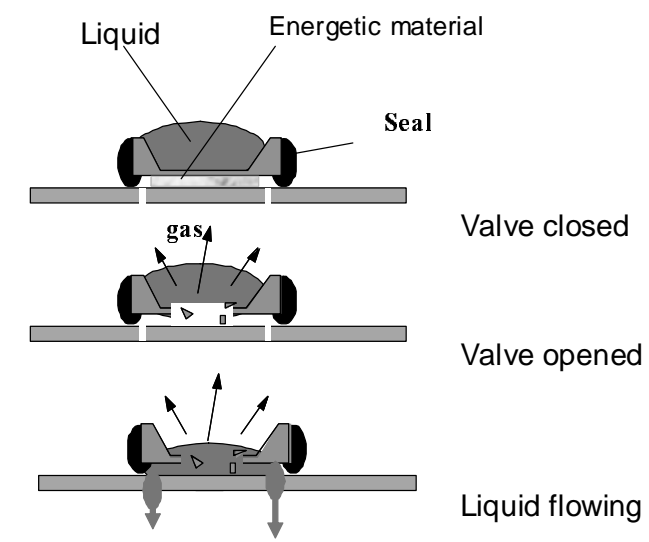

(a)

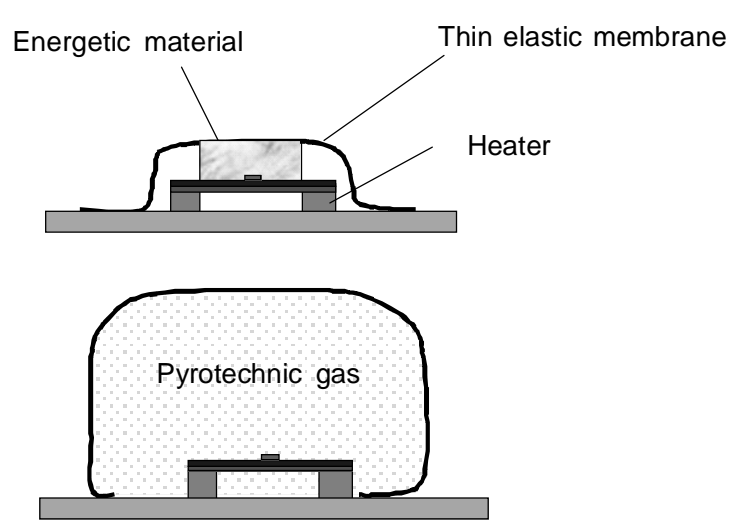

(b)

Figure 8. Illustration of the (a) pyrotechnic microvalve function and (b) pyrotechnic gas generator function 
Two types of drug injection systems based on micropyrotechnics have been developed in LAAS-CNRS, for drug injection application.

\subsubsection{Automatic transdermal patch}

A system for rehydration of transdermal patches has been designed based on 3 pyrotechnic actuators: two oneshot microvalves and one gas generator [55][56] (see Figure 9). The microvalves are activated first, unsealing the reservoir; the gas generator then pushes the drug through the opened microvalves to rehydrate the transdermal patch. The system is flexible so as not to decrease the adherence of the patch to the patient.

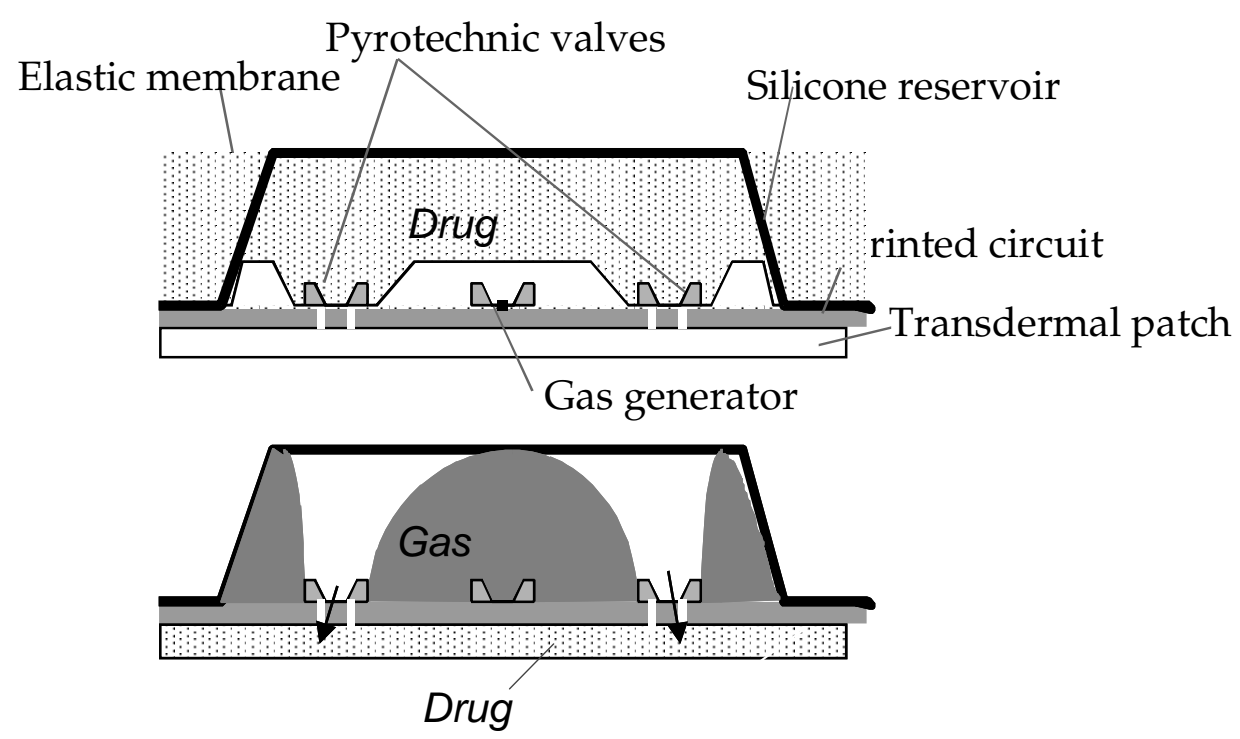

Figure 9.Scheamtic view of a pyrotechnic transdermal patch

This type of system is particularly attractive because it may be activated by an electrical control without the patient's manual intervention. It is inexpensive and well adapted to the current demand for disposable systems.

\subsubsection{Pyrotechnically driven microsyringe}

An interesting solution to stimulate transdermal molecular injection consists of producing arrays of microsyringes based on silicon technology [60][61][62][63][64][65][66]. These semi-invasive injection systems are disposable and are interesting if the reservoir portion and injection system are also miniaturized and inexpensive. In this context, classic syringes or mechanical piston systems cease to be satisfactory. Puig et al [57] have proposed a system of microinjection via a pyrotechnic gas generator that can be integrated on silicon micro machined microsyringe arrays. The operating principle is as follows: once the injection has been programmed, a pyrotechnic gas generator is activated and generates a pressure in the combustion chamber. 
When the pressure reaches $20 \mathrm{MPa}$, a specifically dimensioned membrane ruptures and transmits the pressure to the drug that then goes through the microneedles.

A schematic of the injection microsystem based on pyrotechnics [57] is given in Figure 10.

- The top level is the pyrotechnic gas microgenerator.

- The intermediate level is the injection component that contains a gas expansion chamber, a membrane and the drug reservoir.

- The bottom level is the microsyringe array.

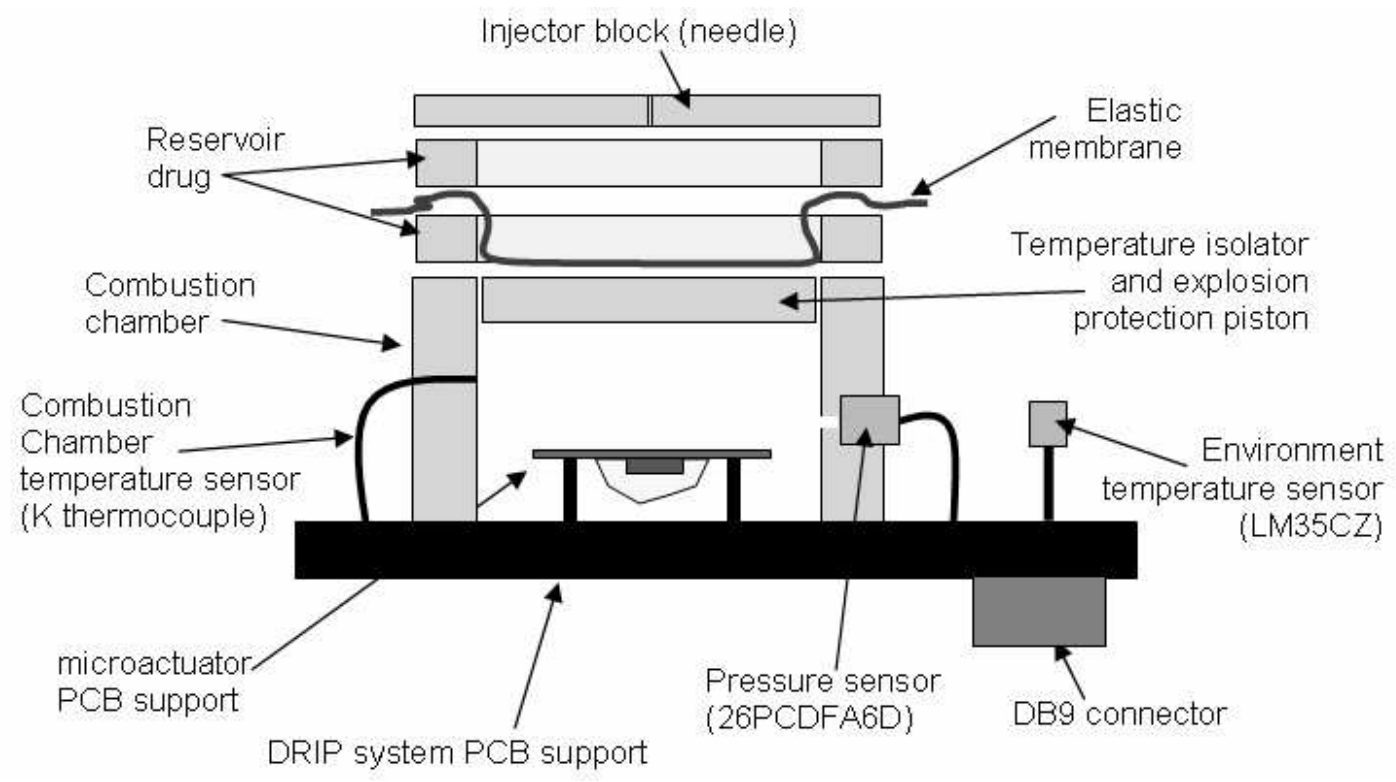

Figure 10. Schematic view of a pyrotechnic injection microsystem adaptable to a microsyringe array

Micropyrotechnics is of great interest in the administration of drugs, offering simple and inexpensive solutions. Although currently limited to single-dose injections, it will also be able to offer lightweight pyrotechnic microactuator arrays that will permit the delivery of highly precise proportional and programmable injections. This field will only progress and mature through a close collaboration between researchers and the pharmaceutical industry.

\subsection{Emerging applications}

Other applications are emerging, and especially in the continuation of drug injection systems since these deal with the generation of pressure to drive fluids in biological or chemical microanalysis applications. Hong et al have published their very innovative first research results in this field [42]. In their design, a solid energetic 
material is deposited in a thin layer on a heating resistor integrated on a glass, plastic or silicon substrate. When the fluid actuation becomes necessary, its chemical decomposition is initiated by heating. The produced gases then push the fluid in the channel as shown in Figure 11. The innovation and interest of this study, compared to previous studies on pyrotechnic actuators published in 1997 [20], are based on two main points:

- Pressure control: the material decomposes as a function of the heating temperature, so that it is possible to control and manage the actuating pressure in real time by controlling the electrical power. Whereas, in first generation pyrotechnic actuators [19], pressure was not controlled in real time but fixed as a function of the ratio of the initial propellant volume to the total initial volume.

- Level of integration: the size of the system is extremely compact $(100 \mu \mathrm{m}$ by $100 \mu \mathrm{m})$ and can be fully integrated.

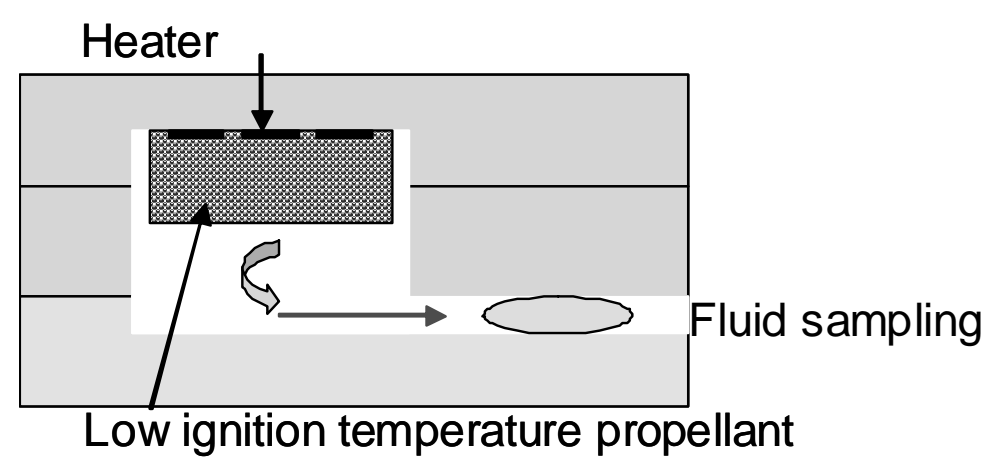

\section{Figure 11. Schematic view of a pyrotechnic actuator by Hong et al [42].}

This study opens up real possibilities for applications in micro fluid actuating, and responds to a pressing demand in biology and chemistry as part of the development of the lab on a chip systems. Other studies have recently been published in the micro fluid actuating field. Weng [58] has presented a gas microgenerator $\left(\mathrm{CO}_{2}\right.$ and $\mathrm{NH}_{3}$ ) for biochips applications. The principle is based on the decomposition of an ammonium bicarbonate powder $\left(\mathrm{NH}_{4}\right) \mathrm{HCO}_{3}$ which, when heated to $60^{\circ} \mathrm{C}$, decomposes into $\mathrm{NH}_{3}$ gas, $\mathrm{CO}_{2}$ and $\mathrm{H}_{2} \mathrm{O}$. Fluid microactuating via gas generation derived from the controlled decomposition of energetic materials placed into microchannels is for sure very promising. It will advantageously replace the compressed gas systems such as those of Choi et al [59] that require a hermetically sealed cavity and a heating system that ruptures the hermetic membrane during actuation.

The second emerging and very promising application is the micro generation of specific gases. A « pyrotechnic micro reservoir » of $\mathrm{H}_{2}$ that feeds combustible micro battery for the generation of electricity has been patented [29]. The thermal decomposition of the energetic material releases gas at pressure and output levels compatible 
with the functioning of the battery. Yields go from 8 to $10 \%$ in mass, which remains interesting compared to other stocking technologies and opens up possibilities for miniature devices.

The last micropyrotechnic application that we will mention in this article is the micro generation of electrical power derived from the combustion of energetic materials using the Seebeck effect. Some teams are looking into the fabrication of thermo-electric microgenerators having a micropyrotechnic heat generating module (hot source), a silicon block (cold source) and a Seebeck conversion module integrated between the hot and cold sources. Two very similar and original projects merit to be mentioned:

- Lindsay et al [39] have proposed a thermoelectrical device whose hot source is generated by the combustion of a propellant. In the best of cases and during the combustion, a DC voltage of $1.2 \mathrm{~V}$ by junction p-poly/n-poly have been measured. By placing a known resistor in series with the thermopile, the total measured power at the outlet of the 10 junctions can reach values of $10-20 \mu \mathrm{W}$. In extrapolating for a $12 \times 10$ junctions matrix, several hundreds of $\mu \mathrm{W}$ could be generated.

- Rossi et al have devised a micropyrotechnic thermoelectric microgenerator [71]. A propellant is contained in a reservoir in the center of the structure. An integrated heating resistor initiates its combustion andcombustion gases are used to heat a block of silicon up to $400^{\circ} \mathrm{C}$ by circulating inside micro channels. Thermocouples in polysilicon/aluminium are positioned between the hot silicon block and the ambient temperature silicon around, thus generating a voltage.

\section{OUR ANALYSIS}

Ever since its beginnings in the mid $90 \mathrm{~s}$, micropyrotechnics have followed the general trend of systems: increasing miniaturization and diversification of the application domains.

Miniaturization: the first pyrotechnic systems had volumes of a few cubic millimeters; today, for similar applications, the dimensions are less than $1 \mathrm{~mm}^{3}$. Down to the $1 \mathrm{~mm}^{3}$ size, propellants or other off-the-shelf or boosted-by-metallic-charges energetic materials were sufficient for the needs and specifications. Below the 1 $\mathrm{mm}^{3}$ size, we reach the limits for the use of these materials, and research teams seem to be turning toward the search for and formulation of new energetic materials in order to obtain performances compatible with the requirements of the applications. Additional steps will be necessary working at the atomic level to develop new energetic molecules compatible with the microelectronic processes of deposit, for which the exothermal 
decomposition can be controlled and adjusted with the temperature. This will then open the way to thermal or mechanical actuating systems that are precise and controllable in real time. In this context, one domain appears extremely promising because it will accompany and stimulate this progress: microfluidic actuating combined with the fabrication of pyrotechnic pressure microgenerators that are adjustable, controllable and very compact.

The diversification of applications is also very important. The role of micropyrotechnics in power micro actuating is very clear: it can heat, connect, disconnect, move solids, liquids and gases, and even bring a supplement of electrical energy. By examining the status of technologies presented here, we clearly demonstrate that this new technology and the microelectronic/microsystems technologies are compatible. There remain applications that will require complex integrations. Thus integration is the process that needs to be researched and prioritised in the next few years. Micropyrotechnics has undergone important progress in the last few years: several applications have been identified and are being developed for the implementation of elementary functions. We believe we must aim for the integration of multiple micropyrotechnic functions and have these functions coexist with other electronic, mechanical and chemical functions.

Concerning the fundamental research and besides the work on the energetic material itself, it seems very important now that the aspect of the management of the thermal energy shall be addressed especially for microfluidics application. for example, one must know how to use the most efficiently, the gas energy to push or make liquid flowing without heating the closest environment.

\section{ACKNOWLEDGEMENT}

The authors would like to thank all the Micropyros project ${ }^{4}$ team as well as the persons that are or have been involved in the works described in this paper especially Dr. Benoit Larangot and Prof. Medhi Djafari Rouhani. Authors acknowledge also the LAAS-CNRS microfabrication team for its support since the beginning of micropyrotechnics activity at LAAS-CNRS. We thank the European commission, ESA and CNES for its fundings.

\section{BIBLIOGRAPHY}

[1] G. Poulin, E. Sarraute, F. Costa, Generation of electrical energy for portable devices: Comparative study of an electromagnetic and a piezoelectric system, Sensors and Actuators A: Physical, Volume 116, 3, 29 October 2004, pp 461-471

\footnotetext{
${ }^{4}$ IST-1999-29047 funded by the European commission
} 
[2] Z. Yang, S. Matsumoto and R. Maeda, A prototype of ultrasonic micro-degassing device for portable dialysis system, Sensors and Actuators A: Physical, Volume 95, 2-3, 1 January 2002, pp 274-280

[3] L. Cao, S. Mantell and D. Polla, Design and simulation of an implantable medical drug delivery system using microelectromechanical systems technology, Sensors and Actuators A: Physical, Volume 94, 1-2, 31 October 2001, $P$ p 117-125

[4] Distributed Micro-Electro-Mechanical Systems Processing Environment, http://www.darpa.mil/mto/mems/summaries/Projects/The 13.html

[5] Air et Cosmos, Les paris technologiques de la NASA, Avril 2001, page 19

[6] A.A. Berlin, K.J. Gabriel, Distributed MEMS: New Challenges for Computations, IEEE Computationnal Sciences \& Engineering, 12-16, Jan-March 1997

[7] J. Hill, R. Szewczyk, et al, System Architecture Directions for Networked Sensors, ACM 9th Int. Conf on Architectural Support for Programming Language, ACM Sigplan Notices, vol 35, 2000, pp 93-105

[8] B. Warneke, B. Liebowitz, and K.S. Pister, "Smart dust : communicating with a cubic-millimeter computer", Computer, Jan 2001, pp44-51

[9] V. Mehta, J. Smith Cooper, Revue and analysis of PEM fuel cell design and manufacturing, Journal of Power Source, 114, 32, 2003

[10] H. Maynard, J.P. Meyers, Miniature fuel cells for portable power : design considerations and challenges, Journal of vacuum Science \& Technology B 20 (4), 1287, 2002

[11] J.R. Lim, C.K. Huang, J.P. Fleurial, Thermoelectric micro device fabricated by a MEMS-like electrochemical process, Nature Materials 2, 528, 2003

[12] Polymer based photovoltaics : a concept for cost efficient renewable energy, MST News, sept 2003

[13] M. Pasquale, Mechanical sensors and actuators, Sensors and Actuators A: Physical, Volume 106, 1-3, 15 September 2003, pp 142-148

[14] D. Bosch, B. Heimhofer, G. Mück, H. Seidel, U. Thumser and W. Welser, A silicon microvalve with combined electromagnetic/electrostatic actuation, Sensors and Actuators A: Physical, Volumes 37-38, JuneAugust 1993, pp 684-692

[15] D. Niarchos, Magnetic MEMS : key issues and some applications, Sensors and Actuators A: Physical, Volume 106, issues 1-3, 15 September 2003, pp 255-262 
[16] O.r Millet, P. Bernardoni, S. Régnier, P.e Bidaud, E. Tsitsiris, D. Collard and L. Buchaillot, Electrostatic actuated micro gripper using an amplification mechanism, Sensors and Actuators A: Physical, Volume 114, issues 2-3, 1 September 2004, pp 371-378

[17] Y. Sun, D. Piyabongkarn, A. Sezen, B. J. Nelson and R. Rajamani, A high-aspect-ratio two-axis electrostatic microactuator with extended travel range, Sensors and Actuators A: Physical, Volume 102, issues 12, 1 December 2002, pp 49-60

[18] W. Van der Wijngaart, H. Ask, P. Enoksson and G. Stemme, A high-stroke, high-pressure electrostatic actuator for valve applications, Sensors and Actuators A: Physical, Volume 100, Issues 2-3, 1 September 2002, pp 264-271

[19] C. Rossi, D. Estève, Pyrotechnic micro actuators, EUROSENSORS XI, Varsovie (Pologne), $21-24$ Septembre 1997

[20] C. Rossi, D. Estève and C. Mingués, Pyrotechnic actuator: a new generation of Si integrated actuator, Sensors and Actuators A: Physical, Volume 74, Issues 1-3, 20 April 1999, pp 211-215

[21] C.Rossi, D.Estève, N. Fabre, T. Do Conto, V.Conédéra, D.Dilhan, Y.Guélou, A new MEMS based microthrusters for microspacecraft applications, Proceedings of the Micro/Nanotechnology for Space Applications (MNT'99), Pasadena (USA), 10-15 April 1999

[22] D. H. Lewis Jr., S. W. Janson, R. B. Cohen and E. K. Antonsson, Digital Micropropulsion, Sensors and Actuators A: Physical, Volume 80, issue $2, \quad 10 \quad$ March $\quad 2000, \quad$ pp $\quad 143-154$ [23] G. Lamedica, M. Balucani, A. Ferrari, P. D. Tromboni, M. Marchetti, Microthruster in Silicon for aerospace application, IEEE AESS Systems Magazine, September 2002, pp22-27

[24] H. H. DiBiaso , B. A. English and M. G. Allen, Solid-phase conductive fuels for chemical microactuators, Sensors and Actuators A: Physical, Volume 111, Issues 2-3, 15 March 2004, pp 260-266

[25] E. Diaz, P. Brousseau, G. Ampleman, E.E. Prud'homme, Polymer Nanocomposites from Energetic Thermoplastic Elastomer and Alex ${ }^{\circledR}$, Propellant, Explosives, Pyrotechnics, 28, 2003, $N^{\circ} 4$

[26] T.M. Tillotson, A.E. Gash, R.L. Simpson, L.W. Hrubesh, J.H. Satcher Jr, J.F. Poco, Nanostructured energetic materials using sol-gel methodologies, Journal of Non-Crystallline Solids 285, 2001, pp338-345

[27] K. Engelen, M. H. Lefebvre, Properties of Gas-Generating Mixtures Related to different fuel and Oxidizer Composition, Propellant, Explosives, Pyrotechnics 28, 2003, $N^{\circ} 4$, pp49-76

[28] Patent FR2845858, Dispositif de remplissage de zone ouvertes situées en creux par rapport à une surface [29] Patent FR2 818 808, Pile à combustible pour l'alimentation d'appareils électroniques, notamment portables 
[30] A.N. Ali, S.F. Son, M.A. Hiskey, D.L. Naud, Novel High Nitrogen Propellant Use in Solid Fuel Micropropulsion, Journal of Propulsion and Power, Vol 20, $N^{\circ} 1$, Jan-Feb 2004

[31] Patent FR9614230 / EP97947111.7, Vanne miniature pour le remplissage du réservoir d'un appareil d'administration transdermique de médicament

[32] Patent FR9706613, Vanne miniature et son procédé de fabrication

[33] D. W. Youngner, S.T. Lu, E. Choueiri, J.B. Neidert, R. E. BlackIII, K. J. Graham, D. Fahey, R. Lucus, X. Zhu, MEMS Megapixel Micro-thruster arrays for small satellite StationKeeping, 14th Annual/USU Conference on Small satellite, 2000

[34] K. Takahashi, H. Ebisuzaki, H. Kajiwara, T. Achiwa, K. Nagayama, Design and Testing of Mega-Bit Microthruster arrays, Nanotech AIAA conference, Houston, 9-12 Septembre 2002

[35] B. S. Tanaka, R. Hosokawa, S. Tokudome, K. Hori, H. Saito, M. Watanabe and M. Esashi, MEMS-Based Solid Propellant Rocket Array Thruster with Electrical Feedthroughs, Transactions of The Japan Society For Aeronautical and Space Sciences, Volume 46, 2003, pp 47-51

[36] Y. Zheng, Z. Gaofei, L. Baoxuan, H. Songqi, Design, Fabrication and Test of MEMS Propulsion with Solid Propellant, 4th round table on micro/nano technologies for space, ESA-ESTEC, Mai 2003

[37] Y. Zhao, B.A. English, H. DiBiaso, G. Yuan, M. G. Allen, Polymeric microcombustors for solid-phase conductive fuel, Sensors and Actuators A: Physical, Volume 111, Issues 2-3, 15 March 2004, pp 260-266

[38] D. Teasdale, V. Milanovic, P. Chang, K. Pister, K. Bohringer, Microrocket for smart dust, Smart Materials and structure, $10(6), 2001, \mathrm{pp} 1145-1155$

[39] W. Lindsay, D. Teasdale, V. Milanovic, K. Pister, C. Fernandez-Pello, Thrust and electrical power from solid propellant microrockets, Technical-Digest.-MEMS-2001.-14th-IEEE-International-Conference-on-MicroElectro-Mechanical-Systems,.2001, 606-10. Piscataway, NJ, USA

[40] P.Q. Pham, D. Briand, C. Rossi, N.F. De Rooij, Downscaling of solid propellant pyrotechnical microsystems, Proceeding Transducers'03, June 8-12, 2003, Boston, pp 1423-26

[41] B.A. English, Microcombustor based on controllable solid fuel element, Proceedings of IMECE'03, 2003

[42] C.C. Hong, S. Murugesan, G. Beaucage, J.W. Choi, C.H. Ahn, A functionning on-chip pressure generator using solid chemical propellant for disposable lab-on-a-chip, Lab-on-a-Chip, Nov. 2003, 3(4), pp 281-286

[43] T. Troianello, Precision foil resistors used as electro-pyrotechnic initiators, Proceedings of the 51st Electronic Components and Technology Conference, 29 May-1 June 2001 
[44] D. S. Stewart, Miniaturization of explosive technology and microdetonics, XXI ICTAM, 15-21 August 2004, Varsaw, Poland

[45] L. Menon, Ignition studies of $\mathrm{A1} / \mathrm{FeO} 3$ energetic nanocomposites, Applied Physics letters, Vol 84, $N^{\circ} 23$

[46] D. S. Stewart, Towards Miniaturization of explosive technology, Shock Waves, 2002, 11, pp 467-473

[47] A. Kasimov and D.S. Stewart, Asymptotic theory of ignition and failure of self-sustained detonations, TAM report $N^{\circ} 1042$, UILU-ENG 2004-6003, ISSN 0073-5264

[48] Patent EP 1098162 - 2001 - SNC Livbag

[49] Patent 2809806 - SNC Livbag

[50] Patent 2809806 - SNC Livbag

[51] Patent EP 1098162 LIVBAG - 2001

[52] B. Larangot, C. Rossi, A. Chaalane , V. Conédéra, P. Dubreuil, P.F. Calmon, Ignition and combustion investigation on pyrotechnical solid microthruster, Proceedings of the 17th European Conference on Solid-State Transducers (EUROSENSORS XVII), Guimarães, Portugal, Septembre 21-24, 2003, pp 744-747.

[53] C. Rossi, D. Estève, P. Temple Boyer, G. Delannoy, Realization, characterization of micro pyrotechnic actuators and FEM modelling of the combustion ignition, Sensors and Actuators, Vol.A70, issues 1-2, October1998, pp 141-147

[54] Patent FR 99.07626, Système de micro propulsion à poudre et procédé de réalisation d'un tel système de micropropulsion

[55] Patent FR9614230 / EP97947111.7, Vanne miniature pour le remplissage du réservoir d'un appareil d'administration transdermique de médicament

[56] Patent FR9706613, Vanne miniature et son procédé de fabrication

[57] M. Puig-Vidal, J. Lopez, P. Miribel-Catala, J. Samitier, C. Rossi, Smart drug delivery system based on pyrotechnical actuation, Proceedings of the SPIE The International Society for Optical Engineering, 2003, 5119, pp226-35

[58] K. Y. Weng, Thermolysis Reaction Actuating Pumps, Proceeding $\mu$ TAS 2001conference

[59] Y. H. Choi, S. U. Son and S. S. Lee, A micropump operating with chemically produced oxygen gas, Sensors and Actuators A: Physical, Volume 111, Issue 1, 1 March 2004, pp 8-13

[60] H.J. Gardeniers, R. Luttge, E.J.W Berenschot, M.J. de Boer, S.W. Yeshurun, M. Hefetz, R. Van't Oever, A van den Berg, Silicon micromachined hollow microneedles for transdermal liquid transport, Journal of Microelectromechanical Systems, Vol12, Issue 6, Dec. 2003, pp 855-862 
[61] A.V. Mukerjee, R.R. Issseroff, S.D. Collins, R.L. Smith, Microneedle array with integrated microchannels for transdermal sample extraction and in situ analysis, TRANSDUCERS, proceedings of the 12th International Conference on Solid-State Sensors, Actuators and Microsystems, 2003 , Vol2 , 8-12 June 2003, pp 1439 - 1441 [62] D.V. McAllister, S. Kaushik, P.N. Patel, J.L. Mayberry, M.G. Allen, M.R Prausnitz, Microneedles for transdermal delivery of macromolecules, Engineering in Medicine and Biology, 1999. 21st Annual Conf. and the 1999 Annual Fall Meeting of the Biomedical Engineering Soc. BMES/EMBS Conference, 1999. Proceedings of the First Joint, Vol 2, 13-16 Oct. 1999, pp 836

[63] S. Henry, D.V. McAllister, M.G. Allen, M.R. Prausnitz, Micromachined needles for the transdermal delivery of drugs, Proceedings of the Eleventh Annual International Workshop on Micro Electro Mechanical Systems, MEMS 98, 25-29 Jan. 1998, pp 494-498

[64] J.G.E. Gardeniers, J.W. Berenschot, M.J. de Boer, Y. Yeshurun, M. Hefetz, R. van't Oever, A. van den Berg, Silicon micromachined hollow microneedles for transdermal liquid transfer, Proceedings of the Fifteenth IEEE International Conference on Micro Electro Mechanical Systems, 2002, 20-24 Jan. 2002, pp 141-144

[65] A. Priyanka, K.V.I.S Kaler, W. Badawy, Design and implementation of MEMS based microneedles for biomedical applications, Proceedings of the Canadian Conference on Electrical and Computer Engineering, 2003. IEEE CCECE 2003, Vol3 , 4-7 May 2003, pp 1505 - 1508

[66] P. Griss, G. Stemme, Novel, Side opened out-of-plane microneedles for microfluidic transdermal interfacing, Prooceedings of the Fifteenth IEEE International Conference on Micro Electro Mechanical Systems, 20-24 Jan. 2002, pp $467-470$

[67] A.K. Dash and G.C. Cudworth, Therapeutic applications of implantable drug delivery systems, $J$. Pharmacol. Toxicol. Methods, 40, 1998, pp 1-12

[68] D.G Allen and M.V. Sefton, A model of insulin delivery by a controlled release micropump, Ann. Biomed. Eng., 14, 1986, pp 257-76

[69] D Maillefer, D, A High performance silicon micropump for disposable drug delivery system, Proceedings of the 14th Annual International Workshop on Micro Electro Mechanical Systems, MEMS 2001

[70] Journées RMNT, November 03, Lilles (France)

[71] Main direction of solid propellant activity at LAAS, Proceedings of CANEUS Micro-Nano-Technologies for Aerospace Applications, 01-05 Nov. 2004, Monterey, California, USA

[72] K.L. Zhang, S.K. Chou, S. S. Ang, Development of a solid propellant microthruster with chamber and nozzle etched on a wafer surface, J. Micromech. Microeng. 14, 2004, pp 785-792 
